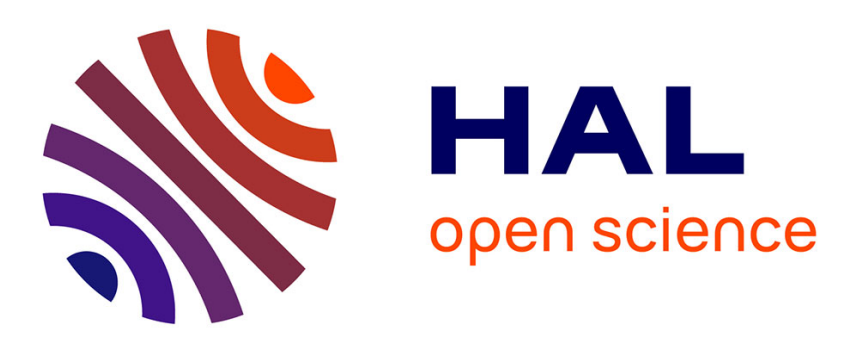

\title{
Formation of localized sand patterns downstream from a vertical cylinder under steady flows: Experimental and theoretical study
}

\author{
Anthony Auzerais, Armelle Jarno, Alexander Ezersky, François Marin
}

\section{- To cite this version:}

Anthony Auzerais, Armelle Jarno, Alexander Ezersky, François Marin. Formation of localized sand patterns downstream from a vertical cylinder under steady flows: Experimental and theoretical study. Physical Review E , 2016, 94 (5), pp.052903. 10.1103/PhysRevE.94.052903 . hal-02074467

\author{
HAL Id: hal-02074467 \\ https://hal.science/hal-02074467
}

Submitted on 20 Mar 2019

HAL is a multi-disciplinary open access archive for the deposit and dissemination of scientific research documents, whether they are published or not. The documents may come from teaching and research institutions in France or abroad, or from public or private research centers.
L'archive ouverte pluridisciplinaire HAL, est destinée au dépôt et à la diffusion de documents scientifiques de niveau recherche, publiés ou non, émanant des établissements d'enseignement et de recherche français ou étrangers, des laboratoires publics ou privés. 


\footnotetext{
*francois.marin@univ-lehavre.fr
}

the experimental findings. The paper ends with conclusions in 53 Sec. IV.

\section{EXPERIMENTAL SETUP AND RESULTS}

The experiments were conducted in a 10-m-long, 0.49-m- 56 wide current flume. The mean water depth $H$ was $0.2 \mathrm{~m} .{ }_{57}$ Current was generated by a recirculating pump, as shown in 58 Fig. 1.

The first series of tests was carried out without sediment 60 and without a cylinder. An acoustic Doppler current profiler 61 (ADCP) was used for these tests to get vertical profiles of the 62 fluid velocity in the channel above the artificial bed which 63 was hydraulically smooth. The flow regime was turbulent for 64 all of the tests since the value of the flow Reynolds number 65 $\operatorname{Re}=\bar{U} H / v$, where $\bar{U}$ is the depth-averaged current velocity 66 and $v$ the water kinematic viscosity, was greater than 5000, 67 the critical value for the flow to be turbulent [11]. The velocity 68 profiles can be described by a logarithmic law characteristic 69 of a turbulent flow, for $z>0.02 \mathrm{~m}$, where $z$ is the vertical 70 distance above the bed (Fig. 2), except for the highest values 71 of $z$ where the outer flow takes place. This logarithmic law 72 may be written as follows,

$$
\frac{\bar{u}}{\bar{u}_{*}}=\frac{1}{K} \ln \left(\frac{z}{z_{0}}\right),
$$

where $\bar{u}$ is the horizontal component of fluid velocity at height 74 $z$ above the bottom, $\bar{u}_{*}$ the shear velocity at the bed, $K$ the 75 Karman constant which is usually taken to be 0.4 , and $z_{0}$ a 76 length scale.

The test conditions are shown in Table I, where $D$ is the 78 cylinder diameter and $\operatorname{Re}_{D}=\bar{U} D / v$. Tests $1-13$ were carried 79 out with a 7-cm sand layer of median diameter $d=340 \mu \mathrm{m} \quad 80$ and relative density $s=\rho_{s} / \rho=2.65$, where $\rho_{s}$ and $\rho$ are the ${ }_{81}$ sand and fluid density, respectively, for flow conditions such as 82 the bed shear stress was too weak to move the sediments when 83 there was no vertical cylinder placed on the bottom. A critical 84 value of $0.31 \mathrm{~m} / \mathrm{s}$ for the depth-averaged current velocity $\bar{U}$ for 85 the initial movement of the sediments has been experimentally 86 obtained. Below this critical value, the sand particles on the 87 


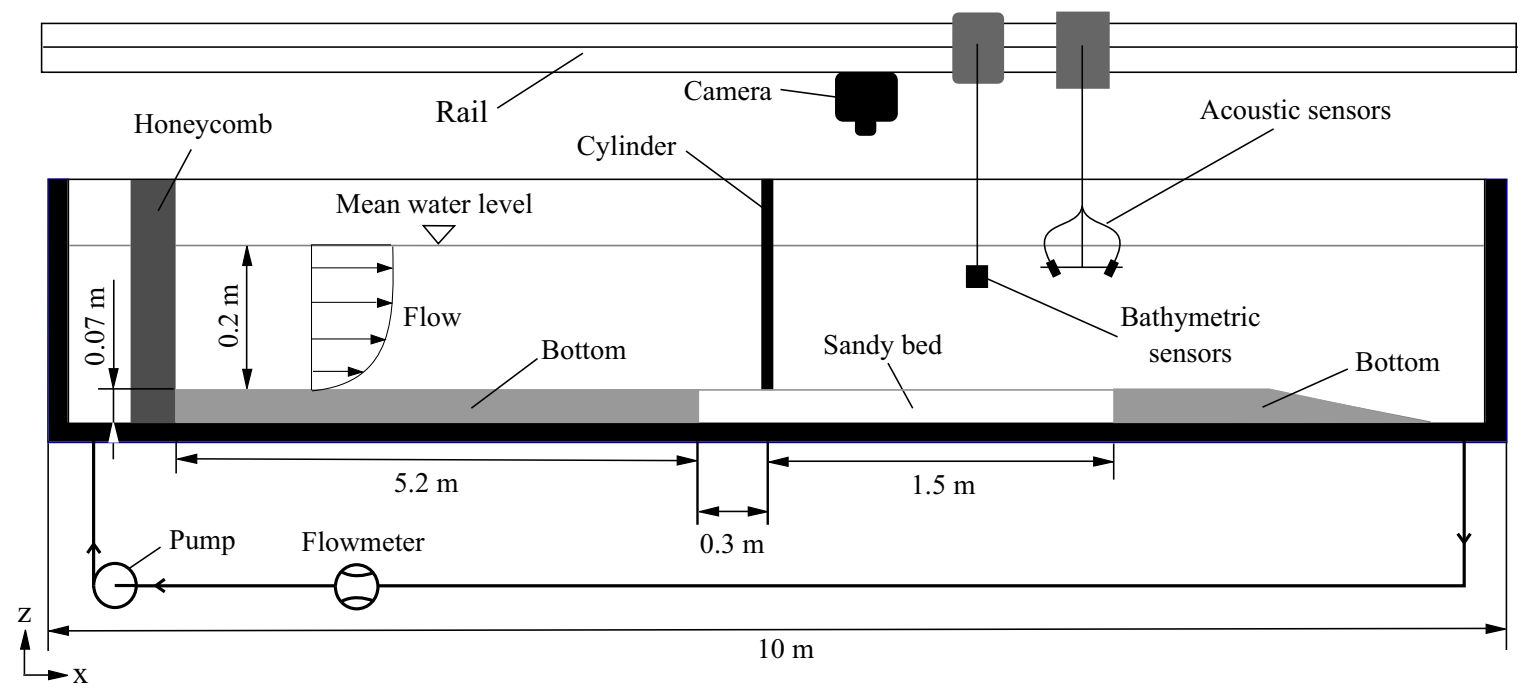

FIG. 1. The experimental setup.

88 bottom are motionless, when sediment transport starts above 89 this value. Let us consider the following relation proposed by 90 Ref. [12],

$$
\theta_{c}=\frac{0.30}{1+1.2 D_{*}}+0.055\left[1-\exp \left(-0.020 D_{*}\right)\right],
$$

91 where $\theta_{c}$ is the critical value of the Shields parameter $\theta$ for 92 the incipient sediment motion, and $D_{*}=\left[(s-1) g / v^{2}\right]^{1 / 3} d$, 93 with $g$ the acceleration due to gravity. The Shields parameter 94 is defined as follows,

$$
\theta=\frac{\tau_{0}}{\rho(s-1) g d},
$$

95 where $\tau_{0}$ is the bed shear stress. Using Eqs. (2) and (3), for 96 the present tests, it is possible to estimate the critical Shields 97 number $\theta_{c}=0.035$, and the critical value of shear velocity 98 at the bed $\bar{u}_{* c}=\sqrt{\tau_{0 c} / \rho}=0.0139 \mathrm{~m} / \mathrm{s}$ for the incipient sedi99 ment motion, with $\tau_{0 c}$ being the corresponding critical value of

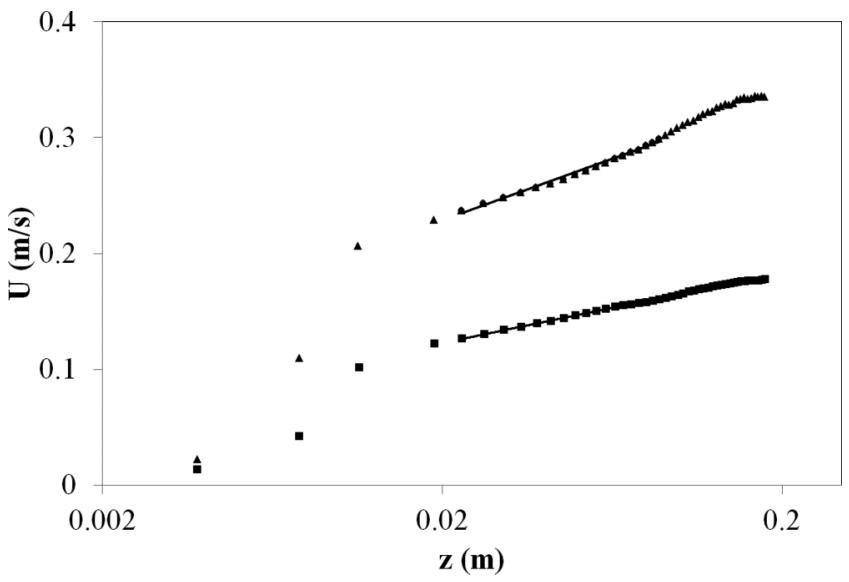

FIG. 2. Typical velocity profiles above the artificial smooth bed, without pile placed on the bed, for a horizontal distance from the honeycomb of $5 \mathrm{~m}$. The solid lines show the best fit with the experimental data in the layer where the velocity profile is logarithmic. $\mathbf{\square}: \operatorname{Re}=29000 ; \boldsymbol{\Delta}: \operatorname{Re}=53000$. $\tau_{0}$. The value of the Reynolds number $\operatorname{Re}_{*}=\bar{u}_{* c} k_{s} / v=11.8, \quad 100$ where $k_{s}=2.5 d$ [13] is the roughness length of the bed, lies 101 in the transition region since $5<\bar{u}_{*} k_{s} / v<70$ [11], and the 102 length scale $z_{0}$ in the log-law velocity distribution [Eq. (1)] ${ }_{103}$ may be estimated by [11]

$$
z_{0}=\frac{k_{s}}{30}\left[1-\exp \left(-\frac{\bar{u}_{* c} k_{s}}{27 v}\right)\right]+\frac{v}{9 \bar{u}_{* c}} .
$$

The bottom is considered to be hydraulically smooth when 105 $\mathrm{Re}_{*}<5$, and hydraulically rough when $\mathrm{Re}_{*}>70$. In the 106 transition regime $\left(5<\mathrm{Re}_{*}<70\right)$, we have [11]

$$
\bar{U}=2.5 \bar{u}_{*} \ln \left(\frac{H}{2.72 z_{0}}\right) .
$$

Using Eqs. (2), (4), and (5), we get an estimation of the critical 108 value of the depth-averaged current velocity $\bar{U}$ for an incipient 109 sediment motion of $0.29 \mathrm{~m} / \mathrm{s}$. This result is in good agreement 110 with the experimentally obtained value of $0.31 \mathrm{~m} / \mathrm{s}$. Table I ${ }_{111}$ shows that the present tests were carried out for $\bar{U}<0.29 \mathrm{~m} / \mathrm{s}, \quad 112$ in other words, for $\theta<\theta_{c}$. A vertical cylinder was embedded ${ }_{113}$ in the sand layer, as shown in Fig. 1. The sandy bottom was 114

TABLE I. Experimental conditions.

\begin{tabular}{lcccc}
\hline \hline Test number & $D(\mathrm{~mm})$ & $\bar{U}(\mathrm{~m} / \mathrm{s})$ & $\operatorname{Re}_{D}$ & $\operatorname{Re}$ \\
\hline 1 & 14 & 0.150 & 2100 & 30000 \\
2 & 14 & 0.190 & 2660 & 38000 \\
3 & 14 & 0.200 & 2800 & 40000 \\
4 & 14 & 0.210 & 2940 & 42000 \\
5 & 14 & 0.215 & 3010 & 43000 \\
6 & 25 & 0.150 & 3750 & 30000 \\
7 & 25 & 0.180 & 4500 & 36000 \\
8 & 25 & 0.185 & 4625 & 37000 \\
9 & 25 & 0.190 & 4750 & 38000 \\
10 & 25 & 0.195 & 4875 & 39000 \\
11 & 25 & 0.200 & 5000 & 40000 \\
12 & 25 & 0.210 & 5250 & 42000 \\
13 & 25 & 0.220 & 5500 & 44000 \\
\hline \hline
\end{tabular}



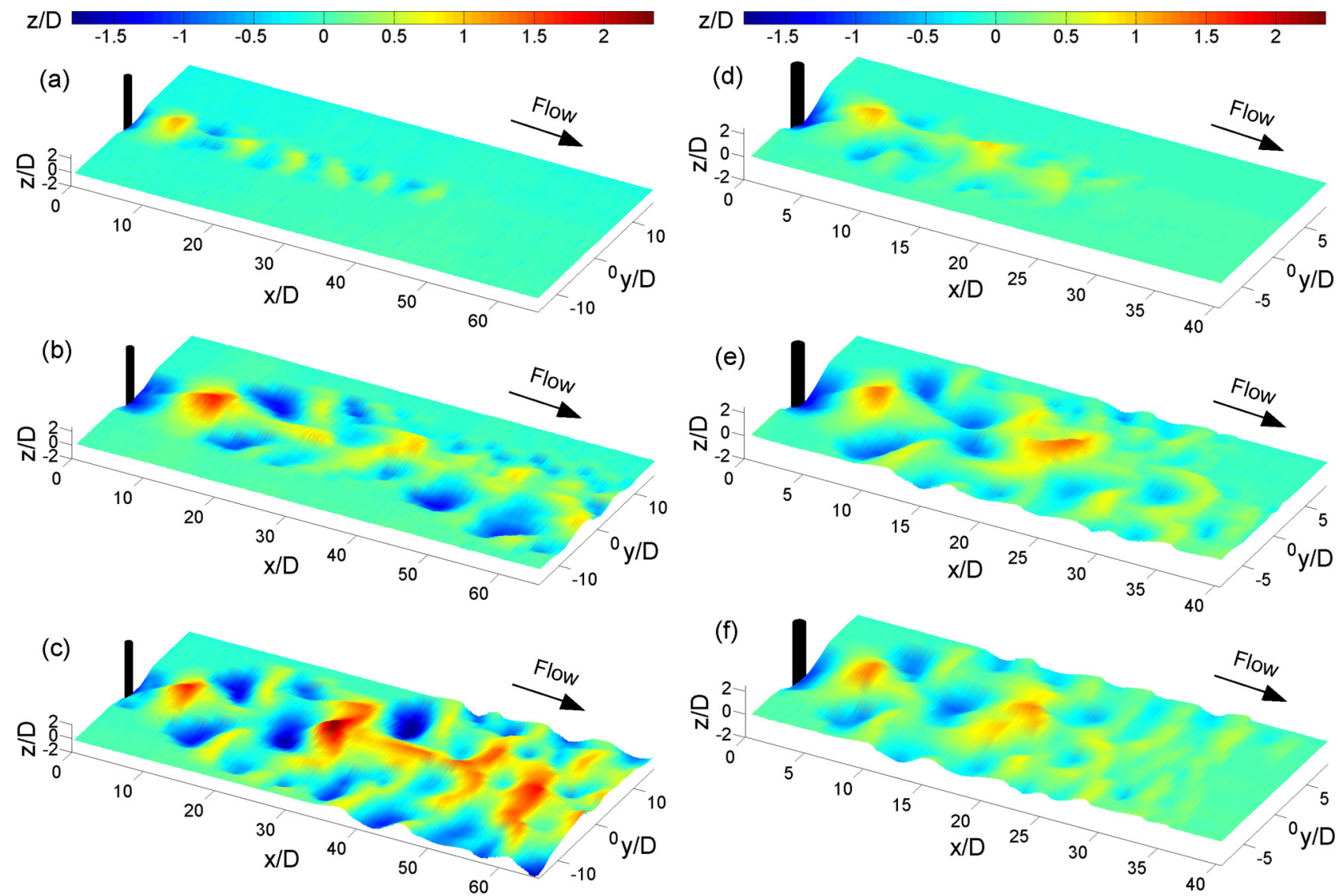

FIG. 3. Bed profiles at the equilibrium state. (a) Test 2, (b) test 4, (c) test 5, (d) test 8, (e) test 10, and (f) test 11.

115 initially flat. It is well known [8] that scour occurs in the 116 vicinity of the cylinder such as

$$
S_{c}=S\left[1-\exp \left(-\frac{t}{t_{*}}\right)\right],
$$

117 where $S$ and $S_{c}$ are the equilibrium scour depth and the 118 value of the scour at time $t$, respectively, and $t_{*}$ is the time 119 scale of the scour process. The value of $t_{*}$ may be estimated 120 from the present tests at $30 \mathrm{~min}$. For our experimental 121 conditions, we have $2100 \leqslant \operatorname{Re}_{D} \leqslant 5500$ (see Table I), and a 122 turbulent Karman vortex street occurs downstream from the 123 vertical cylinder. Measurements carried out with hydrogen 124 bubbles which were produced by electrolysis show that the 125 dimensionless shedding frequency, the so-called Strouhal 126 number $\mathrm{St}=f D / \bar{U}$, where $f$ is the frequency of vortex 127 shedding, is $\mathrm{St} \cong 0.2$. This value agrees well with well-known 128 experimental data [14]. Bedforms appeared downstream from 129 the cylinder due to vortices when the sediments did not move 130 upstream from the cylinder (except in its vicinity where scour ${ }_{131}$ was observed), apart for tests 1 and 6 for which the bed 132 remained flat. These two tests involve the lowest value of 133 the depth-averaged current velocity, and the perturbations 134 in the flow velocity field induced by the vortices are too 135 weak to initiate the development of patterns. The intensity ${ }_{136}$ of these perturbations is considered later in this paper. A 137 high-resolution camera was used to get the top views of 138 the sand patterns, and an ultrasonic ranging system with a 139 linear array of transducers mounted on a movable carriage was employed to provide three-dimensional (3D) bed profiles. 140 Figure 3 depicts bed profiles obtained with the ultrasonic 141 ranging system at the equilibrium state. The origins of $x{ }_{142}$ and $y$ are located at the cylinder center. Sand patterns are ${ }_{143}$ clearly seen. For a fixed value of the cylinder diameter $D$, the ${ }_{144}$ area where patterns appear increases for increasing values of ${ }_{145}$ fluid flow velocity, as shown in Fig. 4 for $D=25 \mathrm{~mm}$, figure ${ }_{146}$ displaying a sharp phase transition. For a given value of the ${ }_{147}$ depth-averaged current velocity $\bar{U}$, this area is enhanced for ${ }_{148}$ rising values of the cylinder diameter. This is illustrated in the 149 comparison between experimental and theoretical results in the 150

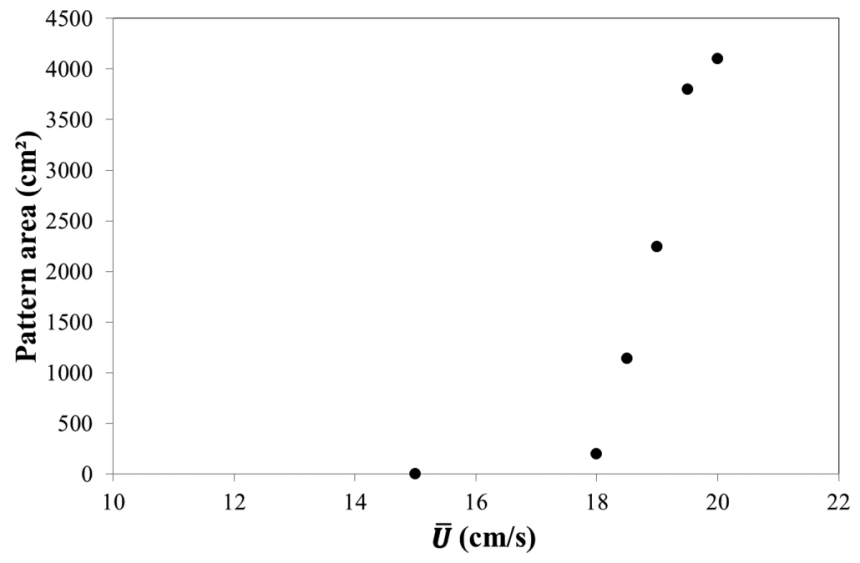

FIG. 4. Variation of pattern area with the depth-averaged current velocity at the equilibrium state. $D=25 \mathrm{~mm}$. 


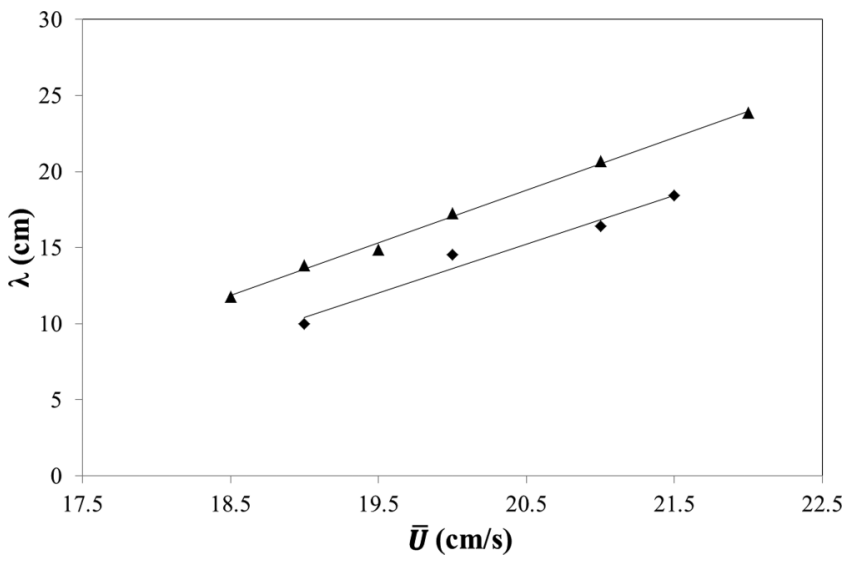

FIG. 5. Variation of the pattern wavelength with the depthaveraged current velocity at the equilibrium state. $\longrightarrow-: D=14$ mm. $\cdots \Delta \cdots: D=25 \mathrm{~mm}$.

171 Figure 8 shows an example of the velocity field for the same 172 flow conditions as test 11, but without sediments on the bed.

${ }_{173}$ Perturbations in the velocity field due to the Lee-wake vor174 tices are clearly exhibited. Time-averaged velocity fluctuation

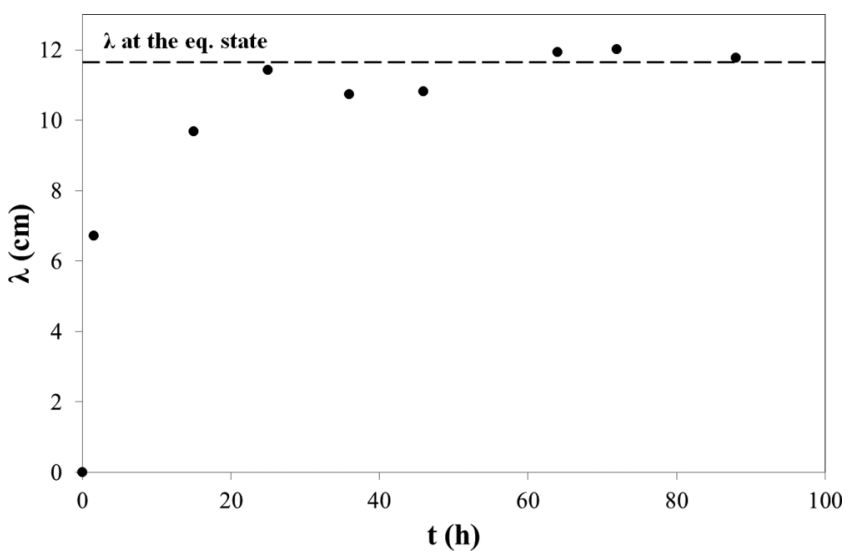

FIG. 6. Variation of the pattern wavelength with time $t$. Test 8 .

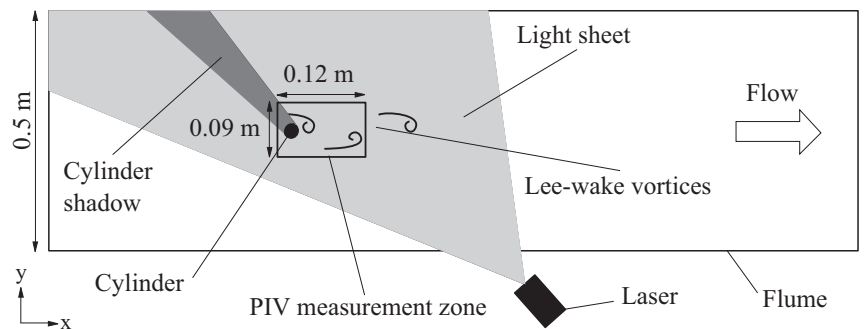

FIG. 7. Sketch of the particle image velocimetry (PIV) system.

fields were estimated using the following equation,

$$
\widetilde{V}^{2}=\frac{1}{T_{i}} \int_{0}^{t}\left\{\left(V_{x}-\bar{V}_{x}\right)^{2}+\left(V_{y}-\bar{V}_{y}\right)^{2}\right\} d t,
$$

where $V_{x}$ and $V_{y}$ are the instantaneous velocity components 176 along the $x$ and $y$ axis, respectively, $\overline{V_{x}}$ and $\overline{V_{y}}$ are the ${ }_{177}$ time-mean values of $V_{x}$ and $V_{y}$, and $\widetilde{V}$ is the time-averaged 178 velocity fluctuation. The integration time $T_{i}$ was fixed to $16 \mathrm{~s}, 179$ which is a time window greater than ten times the time interval ${ }_{180}$ between two vortices shedding for all of the tests. Transverse 181 profiles of $\widetilde{V}^{2}$ are depicted in Fig. 9 for $D=14 \mathrm{~mm}$ and ${ }_{182}$ $x / D=1$. These profiles exhibit two peaks which correspond ${ }_{183}$ to the perturbations induced by the alternate vortex shedding 184 downstream from the cylinder. For a fixed value of $D$, the ${ }_{185}$ intensity of the velocity fluctuations increases for increasing 186 values of $\operatorname{Re}_{D}$, as expected. Figure 9 shows that high values 187 of the velocity fluctuations are located in the wake zone for 188 $-1 \leqslant y / D \leqslant 1$. The variation of $\widetilde{V}^{2}$ with the dimensionless 189 distance from the cylinder in the current direction $x / D$ is 190 plotted in Fig. 10 for $y / D=-0.3$ for the same tests as in 191 Fig. 9. Figure 10 shows that, outside the immediate vicinity of 192 the cylinder, the time-averaged velocity fluctuations decrease 193 quite rapidly for increasing values of the distance $x$ from the ${ }_{194}$ cylinder. As previously mentioned, no pattern appeared for 195 test 1 when the patterns were generated for the other tests 196 carried out with a $14 \mathrm{~mm}$ diam cylinder (tests $2-5$ ). It can be 197 deduced from Figs. 9 and 10 that for $D=14 \mathrm{~mm}$, the patterns 198 on the sandy bottom are not initiated under vortices when the 199 peak values of $\widetilde{V}^{2}$ are lower than $0.008 \mathrm{~m}^{2} / \mathrm{s}^{2}$, approximately, 200

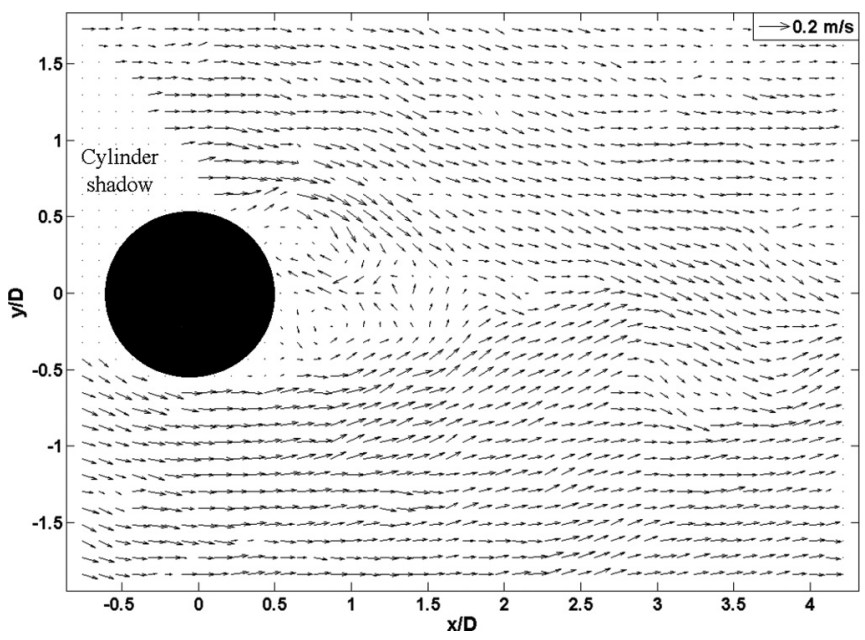

FIG. 8. Velocity field downstream from the cylinder. $\mathrm{Re}=$ $40000, \operatorname{Re}_{D}=5000(z=0.02 \mathrm{~m})$. 


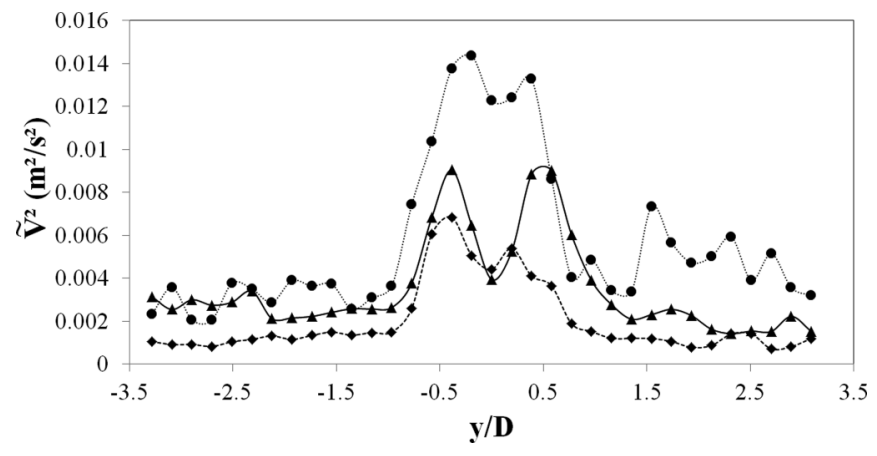

FIG. 9. Variation of $\widetilde{V}^{2}$ [Eq. (7)] with the dimensionless transverse distance from the cylinder $y / D$, for $x / D=1(z=0.02 \mathrm{~m})$. - - -: $\operatorname{Re}_{D}=2100$ (test 1). $-\mathbf{\Delta}-: \operatorname{Re}_{D}=2660$ (test 2). $\cdots \bullet \cdots$ : $\operatorname{Re}_{D}=3010$ (test 5).

201 and that patterns appear when these values are greater than $2020.008 \mathrm{~m}^{2} / \mathrm{s}^{2}$. In the case of the $25 \mathrm{~mm}$ diameter cylinder, 203 the present tests indicate that patterns do not appear for peak 204 values of $\widetilde{V}^{2}$ that are lower than $0.014 \mathrm{~m}^{2} / \mathrm{s}^{2}$, approximately, 205 and do appear when these values are greater than 0.014 $206 \mathrm{~m}^{2} / \mathrm{s}^{2}$ (figure not shown). This confirms that the considered 207 instability leading to the formation of patterns on the sandy 208 bottom downstream from a vertical cylinder is subcritical. For 209 the same value of the fluid flow velocity, the time-averaged 10 velocity fluctuations increase for increasing values of the 11 cylinder diameter, as shown in Fig. 11 for $\bar{U}=0.19 \mathrm{~m} / \mathrm{s}$.

\section{III. THEORETICAL APPROACH}

213 Let us consider the Swift-Hohenberg equation [15], a 214 phenomenological equation,

$$
\frac{\partial u}{\partial T}=\varepsilon u-\left(1+\vec{\nabla}^{2}\right)^{2} u+q u^{2}-u^{3},
$$

215 where $u$ is the order parameter, $\vec{\nabla}=\vec{X} \frac{\partial}{\partial X}+\vec{Y} \frac{\partial}{\partial Y}, X$ 216 and $Y$ are dimensionless distances in the horizontal plan, ${ }_{217} T$ is dimensionless time, $q$ the coefficient for quadratic 218 nonlinearity, and $\varepsilon$ the linear instability of the system,

$$
\varepsilon=\frac{\theta-\theta_{c}}{\theta} .
$$

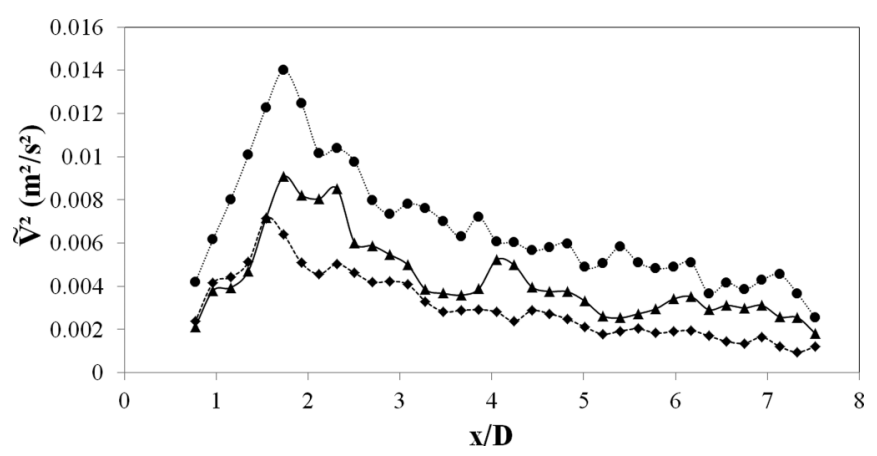

FIG. 10. Variation of $\widetilde{V}^{2}$ [Eq. (7)] with the dimensionless distance from the cylinder in the current direction $x / D$, for $y / D=-0.3$ $(z=0.02 \mathrm{~m}) .----: \operatorname{Re}_{D}=2100$ (test 1$) .-\boldsymbol{\Delta}-: \operatorname{Re}_{D}=2660$ (test 2). $\cdots \bullet \cdots: \operatorname{Re}_{D}=3010$ (test 5).

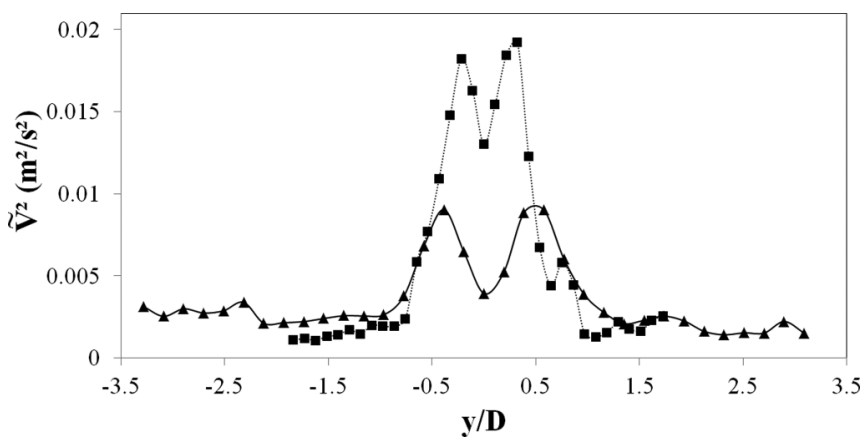

FIG. 11. Variation of $\widetilde{V}^{2}$ [Eq. (7)] with the dimensionless transverse distance from the cylinder $y / D$, for $x / D=1(z=0.02 \mathrm{~m})$. $\bar{U}=0.19 \mathrm{~m} / \mathrm{s} .-\boldsymbol{\Delta}-\mathrm{:} D=14 \mathrm{~mm}$ (test 2$) . \cdots \mathbf{\square} \cdots: D=25 \mathrm{~mm}$ (test 9).

Instability to infinitesimal perturbations occurs if $\varepsilon>0$. If ${ }_{219}$ $\varepsilon<0$, linear instability is absent. The instability occurs for 220 $q>0$, if the initial perturbations are sufficiently large. It is the 221 so-called subcritical instability appearing in many physical 222 systems. The Swift-Hohenberg equation is widely used as a 223 model to describe pattern formation [16,17]. In particular, it 224 has been used to model patterns in fluids such as Rayleigh- 225 Bénard convection.

Equation (8) describes patterns in media which are homo- ${ }_{227}^{226}$ geneous for all directions in the $(\vec{X}, \vec{Y})$ plane. For example, 228 the formation and dynamics of hexagonal or square cells may ${ }_{229}$ be explained by Eq. (8). In the present case, the system is 230 anisotropic in the $(\vec{X}, \vec{Y})$ plane, a flow exists in one direction 231 $(X)$, and Eq. (8) can be modified to describe patterns observed ${ }_{232}$ in experiments in the following way,

$$
\begin{aligned}
\frac{\partial u}{\partial T}= & \varepsilon u-\left[1+\left(\frac{1}{k_{0} D}\right)^{2} \frac{\partial^{2}}{\partial X^{2}}\right]^{2} u \\
& +D_{Y} \frac{\partial^{2} u}{\partial Y^{2}}+q u^{2}-u^{3}
\end{aligned}
$$

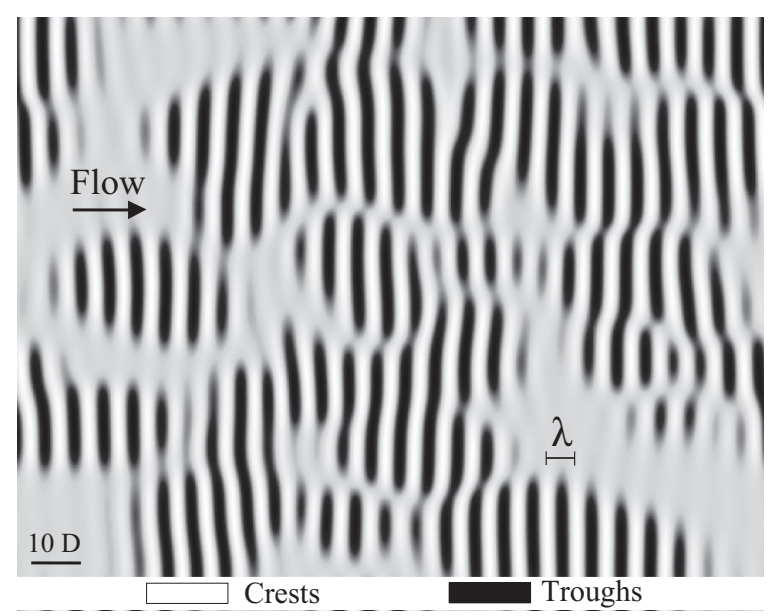

FIG. 12. Theoretical results [Eq. (10)] for $\varepsilon=0.01 . k_{0} D=1$, $D_{Y}=1, q=1.6,20$ iterations. 
${ }_{234}$ where $k_{0}$ is the wave number, $k_{0}=2 \pi / \lambda$, and $D_{Y}$ a diffusion 235 coefficient. For small positive values of $\varepsilon$, Eq. (10) depicts the 236 instability of infinitesimal perturbations with wave numbers 237 oriented along the $X$ direction. This is confirmed by Fig. 12, 238 representing results from Eq. (10) for $\varepsilon=0.01$.

In our case, $\varepsilon<0$ as our experiments are carried out in 240 the subcritical regime, and patterns arise only in the wake of 241 the cylinder where velocity and pressure perturbations initiate 242 instability due to quadratic nonlinearity. We take into account 243 these perturbations by adding a force $f(X, Y)$ corresponding 244 to the time-averaged pressure forces acting on the sand-water 245 interface on the right-hand side of Eq. (10):

$$
\begin{aligned}
\frac{\partial u}{\partial T}= & \varepsilon u-\left[1+\left(\frac{1}{k_{0} D}\right)^{2} \frac{\partial^{2}}{\partial X^{2}}\right]^{2} u \\
& +D_{Y} \frac{\partial^{2} u}{\partial Y^{2}}+q u^{2}-u^{3}+f(X, Y) .
\end{aligned}
$$

${ }_{246}$ We suppose that this force is proportional to $\widetilde{V}^{2}$, where $\widetilde{V}^{2}$ 247 is the spatially modulated random field defined by Eq. (7), 248 because for the values of the Reynolds numbers $\operatorname{Re}_{D}$ (several 249 thousands) involved in our experiments, a turbulent vortex 250 street is observed. The fields of time-averaged velocity fluctu251 ations $\widetilde{V}^{2}$ have been obtained just outside the viscous sublayer 252 for the present tests, using the PIV method as described above. 253 The shape of this force can be qualitatively explained as 254 follows. Along a streamline, we can use the Bernoulli equation,

$$
P+\rho \frac{\widetilde{V}^{2}}{2}=C,
$$

255 where $C$ is a constant. A pressure decrease is induced by an 256 increase of the velocity. Therefore, low pressure corresponds 257 to positive forces acting at the sand-water interface, and 258 these forces introduce perturbations responsible for pattern 259 formation. The diffusion coefficient $D_{Y}$ [Eq. (10)] may be 260 estimated from our experiments with the following equation,

$$
D_{Y}=\left(\frac{l}{D}\right)^{2} \frac{t_{*}}{t_{\mathrm{eq}}}
$$

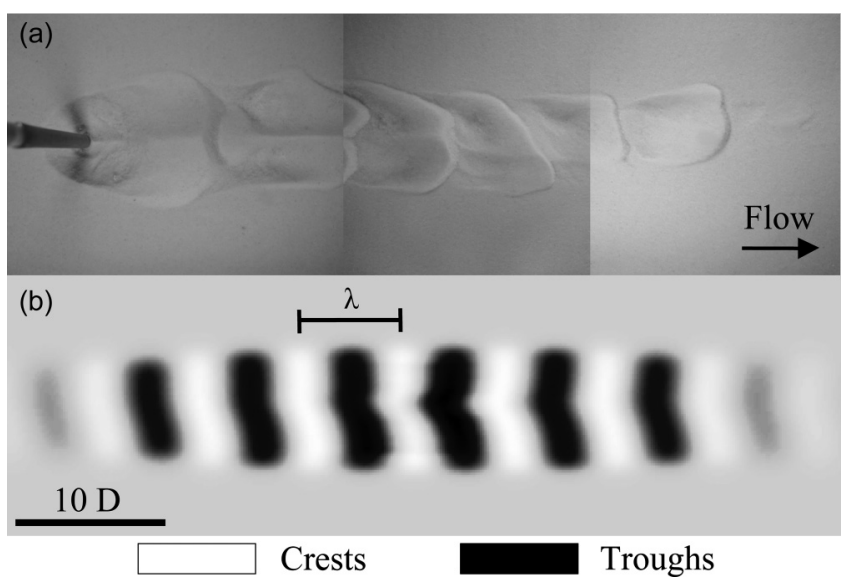

FIG. 13. Comparison between (a) experimental and (b) theoretical [Eq. (11)] results at the equilibrium state. Test 2. $\varepsilon=-0.182$, $k_{0} D=0.94, D_{Y}=0.023$.
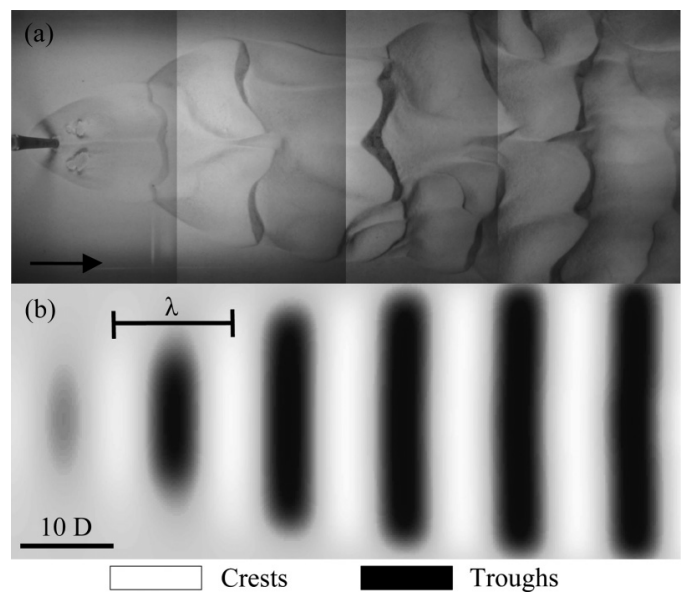

FIG. 14. Comparison between (a) experimental and (b) theoretical [Eq. (11)] results at the equilibrium state. Test 5. $\varepsilon=-0.172$, $k_{0} D=0.50, D_{Y}=0.3$.

In this equation, $l$ is half of the lateral extension (in the $Y_{261}$ direction) of the sand pattern at the equilibrium state, and $t_{\text {eq }} 262$ the time required to reach equilibrium. It should be noted that 263 Eq. (11) can be written in the general gradient form

$$
\frac{\partial u}{\partial T}=-\frac{\delta F}{\delta u},
$$

where $F$ is the free-energy functional,

$$
\begin{aligned}
F= & \int_{\Omega}\left\{\frac{1}{2}\left[\left(1+\left(\frac{1}{k_{0} D}\right)^{2} \frac{\partial^{2}}{\partial X^{2}}\right) u\right]^{2}-D_{Y} \frac{1}{2}\left[\left(\frac{\partial}{\partial Y}\right) u\right]^{2}\right. \\
& \left.-\varepsilon \frac{u^{2}}{2}-q \frac{u^{3}}{3}+\frac{u^{4}}{4}-f(X, Y) u\right\} d X d Y
\end{aligned}
$$

and $\Omega$ is the two-dimensional region of space in which 266 the pattern occurs. The time derivative of this free-energy 267 functional gives us

\section{8}

$$
\frac{\partial F}{\partial T}=-\int_{\Omega}\left(\frac{\partial u}{\partial T}\right)^{2} d X d Y \leqslant 0 .
$$

Free energy may only decrease as it evolves. The limiting 269 behavior for gradient systems is either a steady attractor or 270 propagating fronts. Using the Fourier spatial method, we 271 numerically find nonhomogeneous steady states, as shown 272 below.

Let us compare experimental and theoretical results at 274 the equilibrium state. The value of the coefficient $q$ is 1.6275 for the present simulations, and the number of iterations is 276 500. Figures 13-15 depict the results for tests 2, 5, and 9, 277 


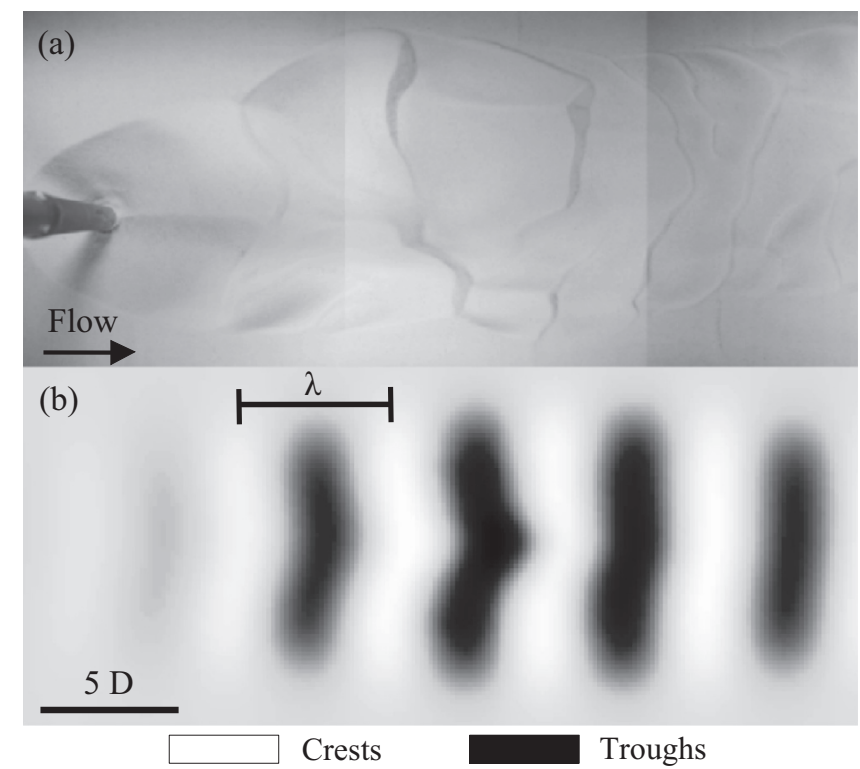

FIG. 15. Comparison between (a) experimental and (b) theoretical [Eq. (11)] results at the equilibrium state. Test 9. $\varepsilon=-0.182$, $k_{0} D=0.78, D_{Y}=0.11$.

278 respectively. A reasonable agreement is obtained between 279 the experimental and theoretical results. In particular, the 280 spatial extension of patterns and the wavelength $\lambda$ are well reproduced. It is not surprising to obtain a greater spatial 281 extension for tests 5 and 9 than for test 2, since tests 5282 and 9 involve higher fluid velocities and a larger cylinder 283 diameter, respectively, leading to larger time-averaged velocity 284 fluctuations, and then to a greater force $f(X, Y)$.

\section{CONCLUSIONS}

286

The formation of localized sand patterns downstream from a 287 vertical cylinder under turbulent steady flows is experimentally 288 and theoretically studied. Tests which were carried out in a 289 hydrodynamic flume depict the generation of patterns as a 290 result of a subcritical instability of the water-sand interface. 291 Lee-wake vortices induced by the cylinder lead to perturba- 292 tions in the velocity field and to an additional force on the sandy 293 bed. The present results show that localized steady states may 294 be numerically obtained by using a modified Swift-Hohenberg 295 equation with an additional term for this force. Numerically 296 obtained pattern characteristics are in reasonable agreement ${ }_{297}$ with experimental observations.

\section{ACKNOWLEDGMENT}

The authors express their sincere thanks to the High Nor- 300 mandy region (Conseil Régional de Haute Normandie, GRR 301 TERA, SCALE Research Network) for funding this work, and 302 to Gaële Perret for her help with the PIV measurements.
[1] J. Lebunetel-Levaslot, A. Jarno-Druaux, A. B. Ezersky, and F. Marin, Phys. Rev. E 82, 032301 (2010).

[2] S. Dey, Fluvial Hydrodynamics: Sediment Transport and Scour Phenomena (Springer, Berlin, 2014).

[3] H. N. C. Breusers, G. Nicollet, and H. W. Shen, J. Hydraul. Res. 15, 211 (1977).

[4] A. W. Niedorada and C. Dalton, Ocean Eng. 9, 159 (1982).

[5] G. J. C. M. Hoffmans and H. J. Verheij, Scour Manual (A. A. Balkema, Rotterdam, 1997).

[6] R. Whitehouse, Scour at Marine Structures: A Manual for Practical Applications (Thomas Telford Publishing, London, 1998).

[7] B. W. Melville and S. E. Coleman, Bridge Scour (Water Resources Publications, Colorado, 2000).

[8] B. M. Sumer and J. Fredsøe, The Mechanics of Scour in the Marine Environment (World Scientific, Singapore, 2002).
[9] R. Ettema, G. Constantinescu, and B. Melville, Evaluation of Bridge Scour Research: Pier Scour Processes and Predictions (Transportation Research Board, Washington, D.C., 2011).

[10] W. G. Qi and F. P. Gao, Sci. China: Technol. Sci. 57, 1030 (2014).

[11] J. F. A. Sleath, Sea Bed Mechanics (Wiley, New York, 1984).

[12] R. L. Soulsby and R. J. S. Whitehouse, Dynamics of Marine Sands (Thomas Telford Publishing, London, 1997).

[13] P. Nielsen, Coastal and Estuarine Processes (World Scientific, Singapore, 2009).

[14] B. Etkin and H. S. Ribner, Canadian research in aerodynamic noise, University of Toronto, UTIA Rev. No. 13 (1958).

[15] J. Swift and P. C. Hohenberg, Phys. Rev. A 15, 319 (1977).

[16] D. J. B. Lloyd, B. Sandstede, D. Avitabile, and A. R. Champneys, J. Appl. Dyn. Syst. 7, 1049 (2008).

[17] M' F. Hilali, S. Métens, P. Borckmans, and G. Dewel, Phy. Rev. E 51, 2046 (1995). 